\title{
Opportunities and challenges of the Internet of Things
}

\author{
Cristina-Andreea NICOLAE \\ Bucharest University of Economic Studies, Bucharest, Romania \\ nicolaeandreea20@stud.ase.ro \\ Mihai Ioan ROȘCA \\ Bucharest University of Economic Studies, Bucharest, Romania \\ mihai.rosca@mk.ase.ro
}

\begin{abstract}
Nowadays, Internet of Things devices are everywhere and their importance and impact on society has increased significantly in the past years. On one hand, Internet of Things devices can bring multiple business opportunities as well as major positive changes to our daily lives. On the other hand, the rapid expansion of the Internet of Things universe comes with important security risks, forcing both users and companies to consider the vulnerability of these devices as well as the confidentiality of the data they generate. The main objective of this paper is to improve current understanding of the Internet of Things by providing a comprehensive overview of the main challenges and opportunities associated with these new communication technologies in various domains and industries. Secondly, the data sets from two Special Eurobarometer studies are analysed to further explore the attitudes, perceptions and experiences of European citizens towards technology and cybersecurity. Using SPSS software, one-way ANOVA and other standard statistical analysis of the data were performed. The results show that the level of awareness of cybercrimes among European citizens has increased. Another key finding is that technology users from European countries remain highly concerned about security issues online. These findings might be of interest for scholars, policymakers, service providers or firms from different industries and can further stimulate the development of local and European initiatives to address and solve these issues.
\end{abstract}

Keywords: Internet of Things, technology, cybersecurity, Europe, connected devices.

\section{Introduction}

Technological innovations have made real progress in the past years and people are now more connected than ever. Kevin Ashton, British technology entrepreneur and one of the creators of Massachusetts Institute of Technology Auto-ID Center, coined the term "Internet of Things" (next IoT) in 1999 (Kramp et al., 2013, p. 1). More than 20 years later, the market for IoT systems has grown significantly, encouraged by both local and international policies and initiatives (for example at European level) as well as the recent scientific literature and experts in the field declaring that there are no limits or barriers to the development of these devices (Wortmann \& Fluchter, 2015; Atzori et al., 2017). In today's digital era, IoT-based products and services are everywhere, becoming one of the fastest growing industries in the world (Tohanean \& Vasilescu, 2019). Statistics estimated that there will be 21 billion IoT devices by 2025 (Symanovich, 2019), while the percentage of American smart homes is expected to grow from 33\% in 2019 to $54 \%$ in 2023 (Payne et al., 2019, p. 1).

As can be seen in Figure 1 below, IoT connected devices and applications come in all shapes and sizes, from smart cars, home appliances or wearables to industrial machinery. However, smart cities remain one of the most surprising and fascinating examples of IoT application, through their complexity and long-term effects. Although there is no universally accepted definition for this term, Sunyaev (2020) defined IoT as "a self-configuring, adaptive, 
complex network that interconnects things which have a physical and virtual representation over the Internet via standard communication protocols" (p. 303). The main role of IoT devices is to collect and exchange large amounts of data, by combining "three main elements: web-based (middle-ware), things-based (e.g. sensors), and semantic-based (knowledge)" (Haddud et al., 2017, p. 1058). According to Roman et al. (2011), the main characteristics of these new communication technologies are "existence, sense of self, connectivity, interactivity and dynamicity" (p. 52).

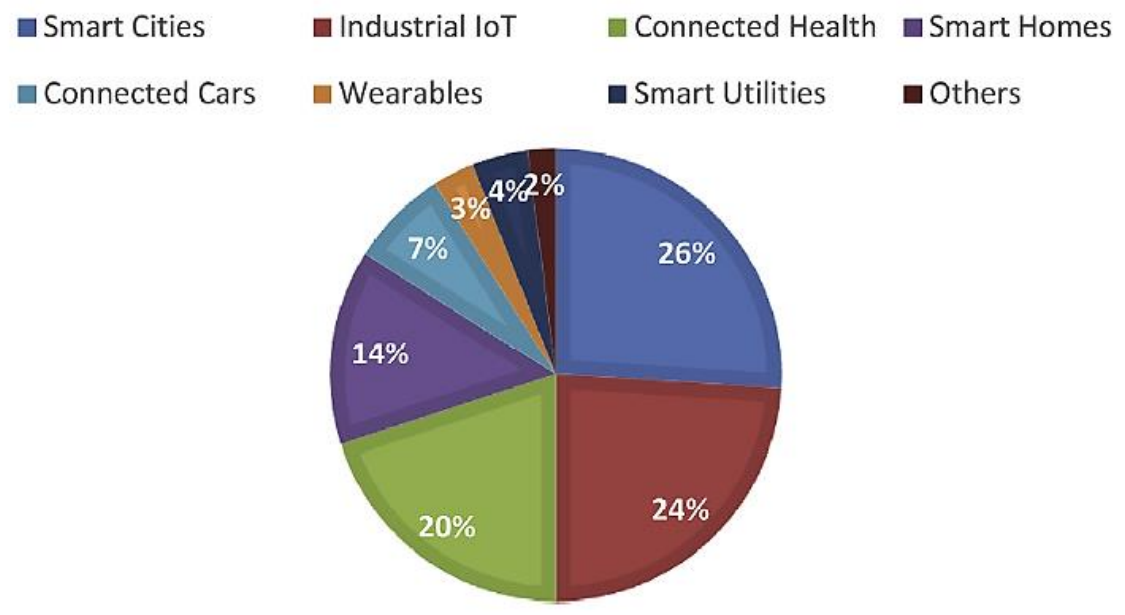

Figure 1. General market structure of IoT technologies

Source: Nižetić et al., 2020, p. 2.

The need to save time and resources as well as maximize profits has supported the application of IoT solutions in many industries and fields, such as the healthcare sector, transport management, education, or supply chain. There is no doubt that IoT systems have now become integrated in the daily lives of consumers and businesses, improving users' quality of life and the overall progress of companies. On the other hand, this increasing use of technology comes with increasing risks, such as data security and privacy concerns. As a result, IoT is considered one of the most challenging research subjects in the area of Information and Communication Technology (Savu et al., 2017). The reality is that all these connected devices have transformed the way people behave, communicate and interact, but also the way we come to care about our own privacy and security online (Marquardt, 2017). The main objective of this paper is to contribute to the existing scientific literature on IoT by exploring the main opportunities and challenges associated with these devices. The second goal of this research is to present and analyse the key opinions, engagement level, and knowledge of citizens living in European Union (EU) countries regarding technology and cybersecurity. The present study has been organized in the following way. The article first introduces main scientific articles on the subject and presents the main advantages and disadvantages associated with IoT. Secondly, two consumer studies are presented and the main results from the data analysis are revealed and explained. Finally, the conclusion offers a summary of the findings and future research directions are identified.

This paper makes several contributions to the current field of studies. To begin with, it covers one concept (IoT) that is extremely volatile and relevant for both present and the future. Because of the increased global interest in modern technology, understanding IoT and data security 
has become a relevant and useful research subject, being an opportune moment to understand this topic. Secondly, taking into consideration the recent increase in criminal activities online, the study delivers a fresh perspective over one understudied topic (the Europeans' attitudes towards technology and cybersecurity). Unfortunately, at the moment "there is not enough information available to guide stakeholders, including new technology designers and policymakers, in dealing with or addressing issues related to cybersecurity" (Addae et al., 2017, p. 560). Understanding what citizens think about criminal activities online and cybersecurity is essential to successful cybercrime policy and critical to success in society's cybersecurity efforts (Cobb, 2018).

\section{Literature review}

\section{Opportunities with the IoT technologies}

According to the participants at the Internet of Things Week 2017, "IoT is emerging as a powerful enabler in many fields and industries, such as water and energy management, environmental monitoring, health, smart cities, smart industry and supply chain management and has the potential to address some of the most acute human, economic and environmental needs" (IoT Week, 2017). The main characteristics and benefits of IoT devices have been researched extensively in the past few years (Savu et al., 2017; López-Vargas et al., 2020; Mohammadian \& Rezaie, 2020). Many researchers have showed that IoT technologies can bring multiple benefits to society including water and energy saving, labour productivity growth, improvement of workplace safety, costefficiency, and reduction of human carbon footprint (Santucci, 2011; Araral, 2020; Espinoza et al., 2020). For example, Salam (2019) declared that IoT is a key enabler for sustainable digital development and environmental protection, while other scholars confirmed that IoT can help with climate change and pollution mitigation, natural resource management and wildlife conservation (Garrity, 2015; Zarei et al., 2016; Beier et al., 2018; Schneider, 2019). To add more, according to the European Research Cluster on the IoT (IERC) report, "the three drivers for development of IoT are increasing the economic prosperity, quality of life and environmental protection" (Zarei et al., 2016, p. 421).

From an environmental perspective, IoT technologies can help to increase transparency about environmental conditions (Schneider, 2019, p. 423) or reduce carbon emissions and pollutions (Maksimovic, 2018, p. 285). It is worth mentioning that some researchers demonstrated that IoT can help achieve the ambitions of the 17 Sustainable Development Goals of United Nations (IoT Forum 2017; Salam, 2019; Fatimah et al., 2020). Salam added that IoT "can make a significant positive contribution to any environmental problem, from reducing water-related disasters and economic losses, to energy efficiency, to better and larger scale connectivity, and effective water management decision making" (2019, p. 4). In contrast to Salam, Lorek and Spangenberg offered an interesting point of view, mentioning that "in view of the environmental challenges people face, slight adjustments to the system based mainly on technological improvements, while promoting environmental modernization and ecological growth are likely to sooner or later face long-awaited disasters" (Lorek \& Spangenberg, 2014, p. 42). The authors added that "economic growth based on technological innovation may be a necessary step towards sustainable development, but it is not enough" (Lorek \& Spangenberg, 2014, p. 42).

The adoption of IoT continues to expand and it is expected to have an enormous impact on consumers, businesses and society (Haddud et al., 2017, p. 1058). Neagu et al. (2017) added that "the complexity and potential uses of IoT will increase significantly in the upcoming future" (p. 6). According to Vodafone's latest IoT Barometer, the industries that saw the greatest increase in IoT adoption are transport and logistics (27\% to 42\%) and manufacturing and industrials (30\% 
to 39\%) (Howell, 2020). With 1,758 companies from all around the world included in the survey, the Barometer also revealed that over a third (34\%) of companies are now using IoT, up from $29 \%$ from the previous IoT Barometer (Vodafone Group, 2019). At national level, the IoT revolution is still in the development phase in Romania, but the number of companies specialized in IoT solutions are on the rise (Rusu, 2017, p. 66). At European level, under the Horizon 2020 Research and Innovation Program, funded by the European Commission, IoT is treated as a focus area (Neagu et al., 2017, p. 6).

There are many industries that have started to incorporate IoT technologies, including fields such as automation and industrial manufacturing, logistics, supply chain management, medical and healthcare industry, and telecommunications industry (Bandyopadhyay \& Sen, 2011). For example, in supply chain management IoT technology has emerged as a lead actor in the development of traceability systems in the food supply chain and their implementations are increasing at a fast rate (Badia-Melis et al., 2015, p. 394). To continue, some of the benefits of using IoT in the healthcare industry include a greater and easier access to health records and related information as well as the improvement in healthcare services quality and cost-efficiency (Thibaud et al., 2018, p. 81). From the perspective of the private user, the main role of these devices is to improve the quality of life, making daily tasks easier for its users (Bandyopadhyay \& Sen, 2011). Gadgets including Alexa, Google Home, ivee, and Mycroft can help with information search, music playing or event planning. Furthermore, security devices based on IoT technology can facilitate personal security, by providing live monitoring of people's houses. To add more, various systems can provide relevant data on the level of environmental pollution while autonomous cars can bring major changes to everyday tasks. This view is supported by Espinoza et al. (2020) who added that "in the consumer side of the economy the IoT can foster security (e.g. the smart home that incorporates home automation components), health (e.g. fitness watches, devices that monitor health and medical gadgets) and efficiency (e.g. connected devices, smart technologies and solutions integrated in roads and bridges that can reduce traffic and energy usage)" (p. 6). However, not all IoT devices invented are that useful, for example Hidrate Spark (a smart water bottle that glows to remind people to hydrate) or SMALT (a smart salt dispenser) (Acante Solutions, 2019).

It can be concluded that the road ahead is a promising one when it comes to technology and certainly worth looking forward to, as IoT continues to change human life. Not only these new communication technologies improve people's well-being and the efficiency of companies, but they can also help with environmental protection. Therefore, can IoT technologies save the planet and help reach societal and environmental prosperity? The next chapter will explore in more detail some of the most important challenges associated with these devices.

\section{Challenges with the IoT technologies}

When it comes to the IoT, the disadvantages are as important as the advantages. Concerns around the security and privacy of IoT systems are at the moment a popular subject of discussion (Zhang et al., 2014; Zamfiroiu et al., 2020). Any object connected to the Internet is prone to cyberattacks and IoT devices are no exception to this rule (Savu et al., 2017). According to Balte et al. (2015) the main challenges related to IoT devices include but are not limited to "devices heterogeneity, scalability, ubiquitous data exchange through wireless technologies, energy-optimized solutions, localization and tracking capabilities, self-organization capabilities, semantic interoperability and data management, and last but not least embedded security and privacy-preserving mechanisms" (pp. 450-451). Similarly, Butun et al. (2019) found that "scalability, transparency and reliability are the most prominent issues to be solved in terms of security-related initiatives" (p. 20). Another 
challenge associated with the IoT is highlighted by Agmon (2019) who declared that "the competitive IoT device market forces vendors to try and get their products out as fast as they can, prioritizing functionality and the user experience, while ignoring the security aspect" (p. 14). Considering IoT layered architecture, Cvitic et al. (2015) have demonstrated that "the first layer (perception one) has the biggest security risk due to the specific limitations of devices and the transmission technology used at this layer" (p. 738).

Roman et al. (2011) warned that "the IoT's anywhere, anything, anytime nature could easily turn daily practices into a dystopia" (p. 54). To add more, Patton et al's study (2014) tried to measure the number of vulnerable devices in the world and find out that vulnerability rates range from a low of $0.44 \%$ to a high of $40 \%$, which means that on a global scale where millions of systems are in use, even the lowest vulnerability rate of $0.44 \%$ would result in 4400 vulnerable systems for every million deployed (p. 234). Similarly, a more recent study from Palo Alto Networks Unit 42 research team found that a staggering $98 \%$ of all IoT device traffic is unencrypted, exposing personal and confidential data on the network (O'Donnell, 2020). At the same time, the number of cyberattacks are expected to increase in the future due to the current rapid adaptation and expansion of IoT devices (Espinoza et al., 2020).

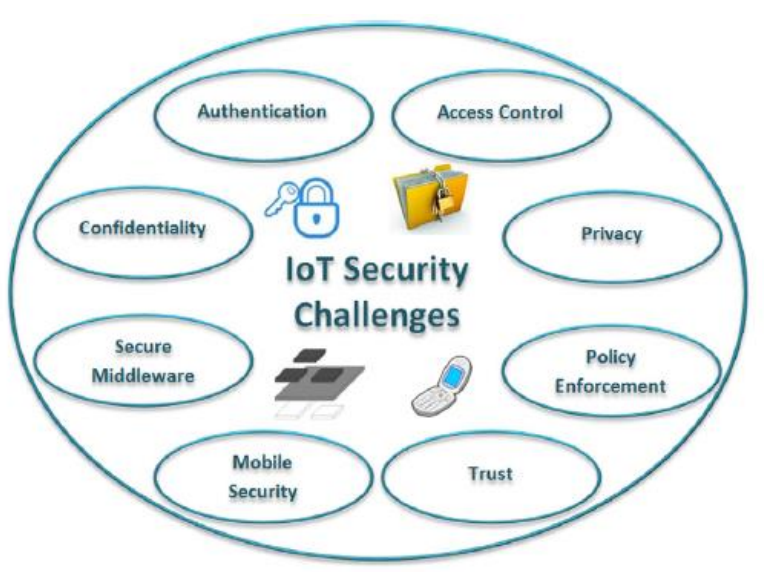

Figure 2. Main security issues in IoT

Source: Sicari et al., 2015, p. 147.

The truth is both companies and individual users are exposed to a high number of risks that exceeded previous expectations. As presented in Figure 2 above, there are several types of cybersecurity threats when it comes to IoT communications. Some IoT security risks can be lifethreatening, while others can destroy internal procedures of firms or collect confidential information. For example, in 2014, 750,000 spam emails were sent by a smart fridge's botnet, while in 2016, one of the most famous attack occurred, the Mirai botnet, which relies on hacking IoT devices by guessing the login credentials, using brute force of small, common usernamepassword pairs (Agmon, 2019, p. 15). It is worth highlighting that most of the time the target of the attack is not necessarily the user of the device, but the company whose data has been disclosed. As noted by Marquardt (2017) "nowadays it is no longer the product that matters but the data that are generated by using the product or service" (p. 789). To remove these challenges, IoT technology requires solid security infrastructure across all its elements from beginning to end, including gadget recognition, maintenance, data management or framework administration (Roman et al., 2011, p. 53). While some specialists argued that without strong security foundations, 
attacks and malfunctions in the IoT will outweigh any of its benefits (Roman et al., 2011, p. 51), others declared that none of the above are likely to outweigh the potential benefits of the IoT (Espinoza et al., 2020, p. 6).

It can be concluded that data privacy and security remain the biggest risks associated with the IoT devices, regardless of the person or company using them or in what industry they are implemented (Roman et al., 2011; Bandyopadhyay \& Sen, 2011). The next part of the paper discusses these challenges from the point of view of European technology users.

PICBE | 1074

\section{Methodology}

The two Special Eurobarometer studies used for data analysis are „Attitudes of Europeans towards the impact of digitisation and automation on daily life” (2017) and „Europeans' attitudes towards cybersecurity" (2017). The first report analysed the attitudes of European citizens towards the effect of technology on everyday life and the economic environment, as well as the actions that users have taken because of online privacy and security issues (Eurobarometer 87.1, 2017). The second report analysed opinions, engagement level, and knowledge of citizens living in European Union (EU) regarding cybersecurity (Eurobarometer 87.4, 2017).

Both European Commission reports were carried out in 2017 in the 28 European Union states (including United Kingdom and Cyprus). The research method utilized in both studies is the face-to-face interview in the respondents' native language and own homes. The sample consisted of EU citizens from different social and demographic categories, reaching around 28,000 respondents for each report. Regarding the gender of respondents, $45 \%$ of them are men while the rest of 55\% are women. Almost 50\% of all respondents are 55 years and older. As noticed in Figure 3 below, there is a negative asymmetric curve regarding the age of respondents, slightly inclined to the right (Skewness coefficient -0.102), with more extreme values to the left (Kurtosis coefficient -0.943).

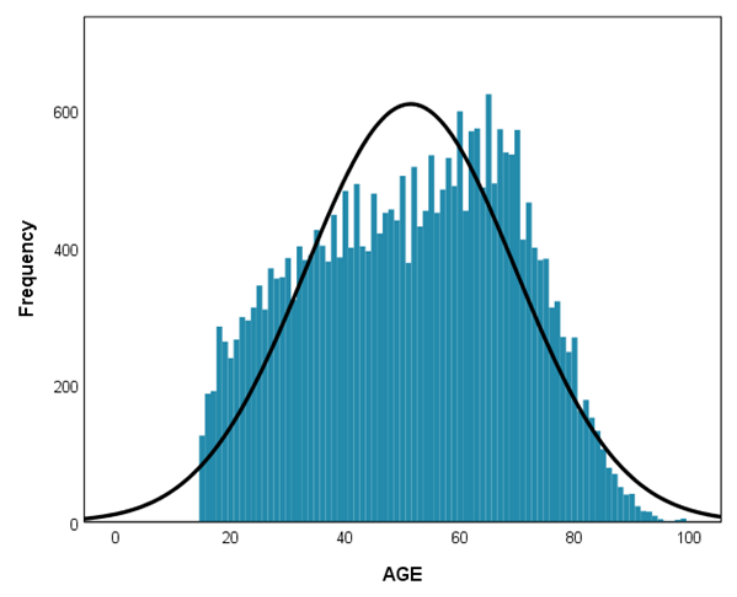

Figure 3. Distribution of respondents' age

Source: Authors' own research results.

The main purpose of data analysis is to examine the attitudes of European citizens towards technology and cybersecurity. This study focuses on Europe because it represents one of the places where large-scale initiatives on IoT has been fostered in recent years (Zarei et al., 2016; Espinoza et al., 2020). According to Santucci (2011) the concept of IoT was adopted by the European Union in the Commission Communication on RFID published in March 2007 (p. 17). The main variables 
measured in the present study are respondents' general attitudes towards digital technologies, robots and artificial intelligence (AI); the role and importance of security and privacy features when purchasing IT products or using digital technologies; respondents' awareness and experiences of cybercrimes; level of information on criminal activities online; and actions taken because of online privacy and security issues. The raw data sets of these two reports were analysed using SPSS software and the main results are discussed next.

PICBE | 1075

\section{Results and discussions}

Overall, most Europeans have a positive attitude regarding the effect of latest digital technology on everyday life and the economic environment (Eurobarometer 87.1, 2017, p. 5). The influence of technology on society is seen as positive and very positive according to two thirds of respondents $(66.5 \%)$, while $67.2 \%$ consider that these technologies have either a very positive or a positive effect on their life quality. Interestingly, respondents in Malta are the most likely to say the impact of technology on their life quality (40\%) and society (36\%) has been very positive.

Interestingly, more than $60 \%$ of all respondents have a fairly positive and very positive view towards robots and AI. It is worth highlighting that study participants are five times more likely to say that the impact of technology is fairly positive than very positive $(51 \% \mathrm{vs} .10 \%)$ (Eurobarometer 87.1, 2017). On the other hand, as can be seen in Figure 4 below, 3 in 10 respondents have a negative view towards robots and AI. These opposing views are in line with previous studies which revealed that "while technology increasingly affects everyone, not all individuals view this trend as positive" (Edison \& Geissler, 2003, p. 138).

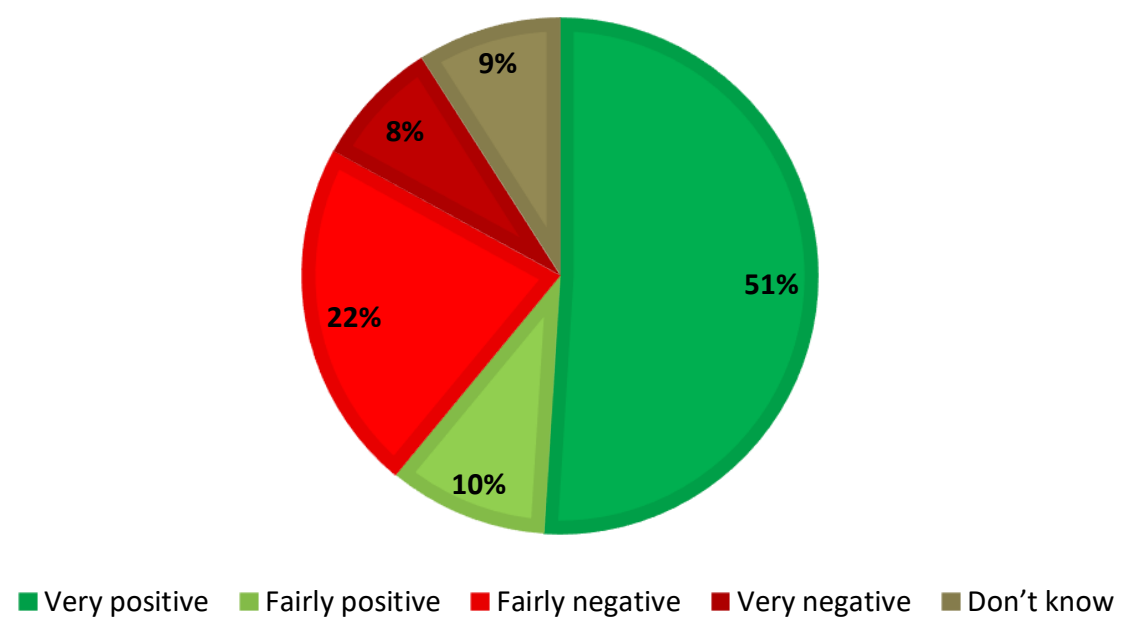

Figure 4. Respondents' view on robots and $A I(N=27.901)$

Source: Authors' own research results.

To add more, almost 1 in 5 respondents have listened, read or watched something about AI in the last year. As can be observed in Figure 5 below, Netherlands (81\%) and Sweden (81\%) are the countries in which most respondents have listened, read or watched AI content in the last year. A possible explanation would be that Western European countries are more exposed to technology and more digitalized compared to the Eastern side. As a comparison, Romania (25\%) and Bulgaria (20\%) are the countries where the least respondents have listened, read or watched AI content in the last year. According to OECD.AI, neither Romania nor Bulgaria have a national strategy for AI implementation in place at the moment (2020). These discrepancies are also confirmed by 
previous studies which demonstrated that different cultures have different attitudes and opinions towards technology (Bartneck et al., 2005).
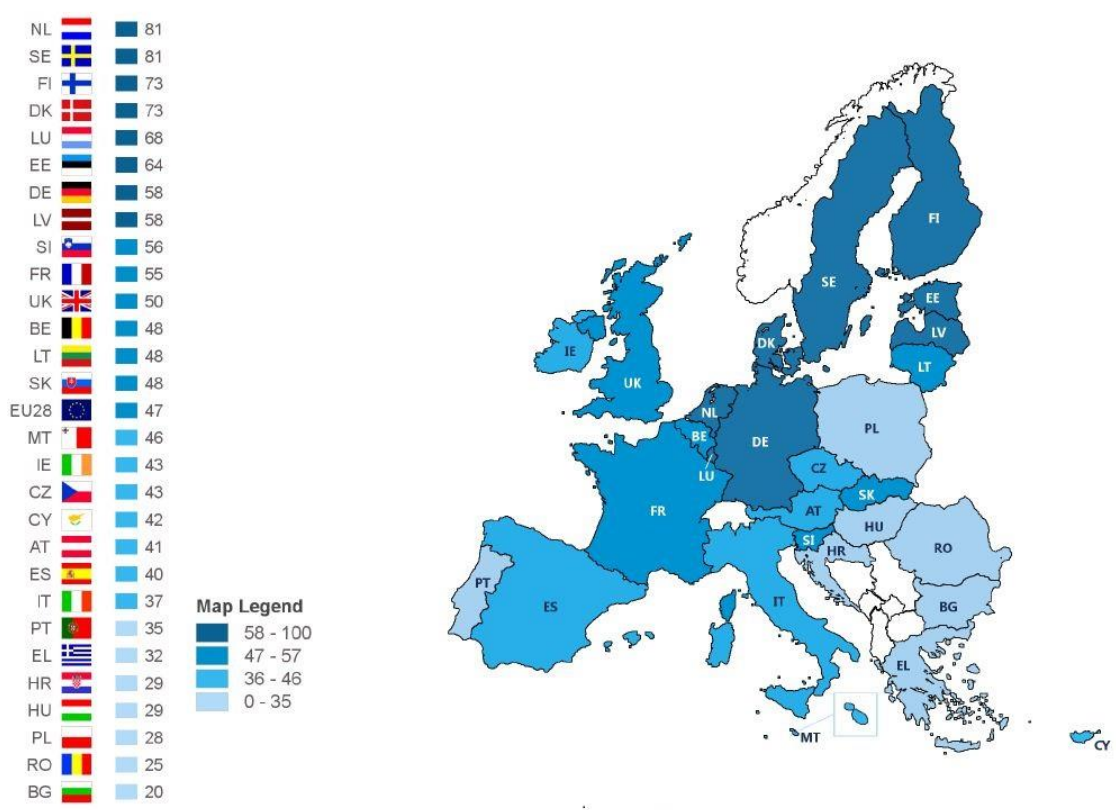

PICBE | 1076

Figure 5. Percentage of respondents who have heard, read, or seen anything about $A I$ in the past year $(\mathrm{N}=27.901)$

Source: Eurobarometer 87.1, 2017, p. 56.

Regarding the frequency of Internet use, $66.1 \%$ of respondents said they use the Internet daily, $10.7 \%$ sometimes, while $21.3 \%$ never and $1.8 \%$ do not have Internet access. These results are in line with previous consumer studies (for example Statista, 2020). However, it is important to note that a higher frequency of Internet use comes with increased security and privacy risks. The results also showed that more and more people are using the Internet for online banking or for shopping compared to previous years, two online services that are very vulnerable to cyberattacks. When it comes to online banking, respondents from countries in the Western side of Europe (Finland and Denmark, both 93\%) are the most likely to do this activity online. To contrast, Romanians (17\%) and Bulgarians (19\%) are the least likely to use the Internet for this activity. Interestingly, more than half of respondents agree that the more widespread use of technologies to secure online services $(63 \%)$ and of tools that improve trust and reputation (58\%) are two factors that will likely encourage them to make more use of digital technologies. It can be observed that the security of personal information and online payments is very important for Internet users. As a result, it can be argued that security measures that prevent attackers from exploiting these vulnerabilities are more important now than ever before because of the growing quantity and sensitivity of data that people are putting online (Payne et al., 2019, p. 1).

The most common actions taken due to security and privacy concerns in the last 3 years by the respondents were using antivirus software (reported by $43.2 \%$ of respondents), using only their personal computer $(39 \%)$, not disclosing personal information on websites $(38.8 \%)$, and only opening emails from trusted sources (36\%). These results confirmed that 1 in 3 respondents are likely to take at least one measure to secure their online identity. To add more, for around $60 \%$ of all respondents privacy and security characteristics play a key role when purchasing computers or 
smartphones and almost $30 \%$ of respondents are willing to pay more for better security and privacy features. It is evident from these results that European users are starting to pay more attention to the information they provide online and how they can keep it safe. As online privacy and network security become a key component of people's lives, the role and involvement of shareholders in the safety deployment of technology across society is crucial. These findings tend to contradict previous studies in the literature which suggested that the ignorance regarding privacy of the general public is one of the main issues of Internet usage (Bandyopadhyay \& Sen, 2011, p. 13) or that the majority of people fail to follow cybersecurity best practices in their own digital lives (Olmstead \& Smith, 2017, p. 4). A possible explanation for these differences might be due to the nationalities or the age of respondents.

Interestingly, over 8 in $10(87 \%)$ Europeans are worried about cybercrime and consider it an important challenge, the proportion increased with 7 percentage points since March 2015 (Eurobarometer 87.4, 2017, p. 5). The percentage is higher when comparing the number of Europeans who say cybercrime is a very important challenge: from $42 \%$ in 2015 to $56 \% 2$ years later (Eurobarometer 87.4, 2017, p. 5). In contrast with these findings, a Pew Research Center study revealed that "most Americans do not express profound worries about cybersecurity in their personal lives or in their expectations for various public institutions" (Olmstead \& Smith, 2007, p. 6). To continue, as seen in Figure 6 below, the top criminal activities online that people are most concerned by are finding malicious software on personal devices and identity fraud (both almost 70\%) (Eurobarometer 87.4, 2017, p. 64). Interestingly, the number of those who picked identify fraud has increased with 17 percentage points since 2013 (Eurobarometer 87.4, 2017, p. 64).

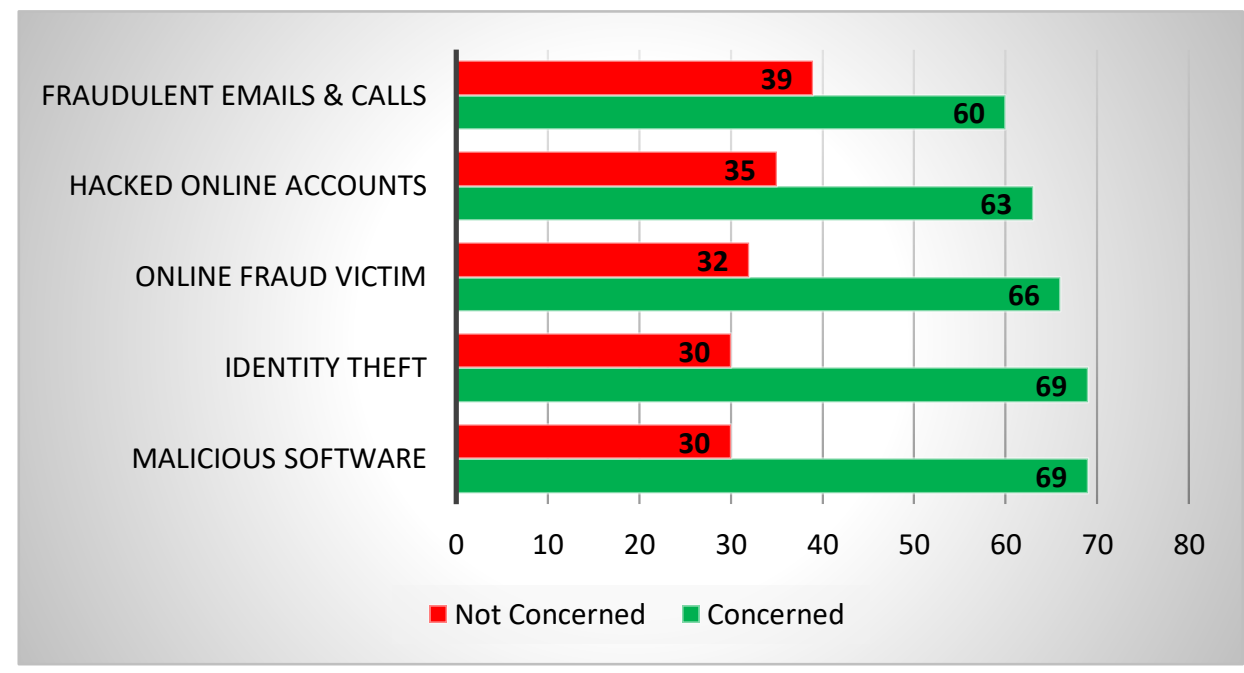

Figure 6. Top cybercrimes respondents are most concerned by $(\mathrm{N}=\mathbf{2 2 . 2 3 6})$

Source: Authors' own research results. 
Considering the level of information regarding cybercrime among European citizens, the results are not very encouraging. As seen in Table 7 below, more than half of Europeans say they are not well informed about criminal activity online, of which 19\% feel not at all informed and the rest of $32 \%$ feel not very well informed. Only 3\% of all respondents do not know their level of information regarding cybercrime. On the other side, more respondents feel they are fairly well informed compared to those who say they feel very well informed. Considering these findings, more actions should be done at EU level to educate Internet users on how to protect themselves against cybercrimes. This lack of information of European citizens regarding cybercrime risks requires urgent solving.

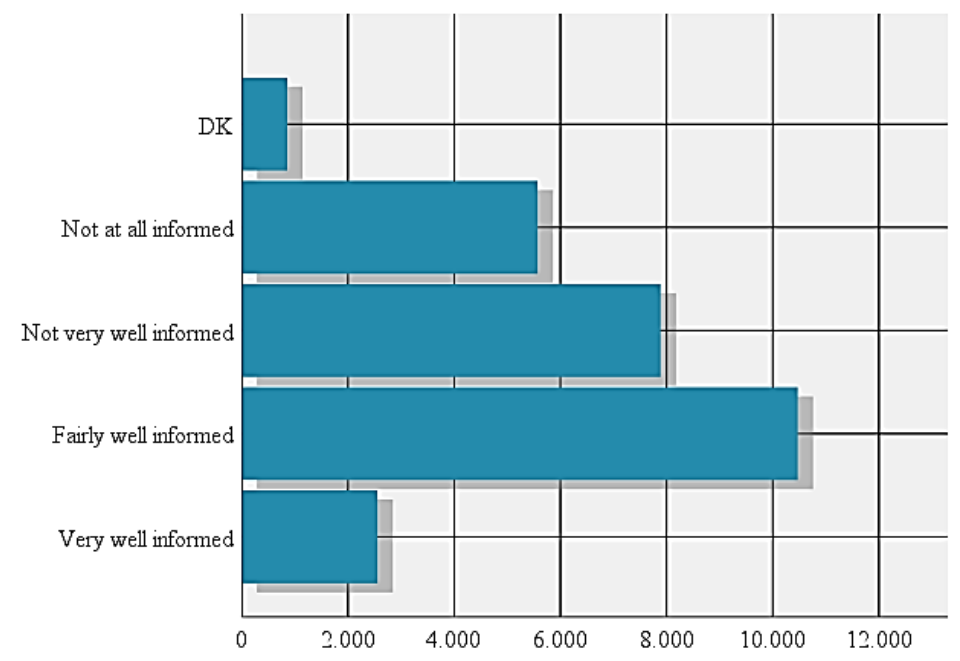

Figure 7. Level of information regarding cybercrime risks $(N=27.901)$

Source: Authors' own research results.

To summarize, four major trends can be identified after analysing the data sets of the two Special Eurobarometer studies: more Europeans are using the Internet on a daily basis; they are using the Internet for activities that carry high security risks; although most of them have taken action to protect personal data online, they are not well informed about cybercrime; and their level of concern regarding cybercrime is increasing compared to previous reports. These results highlight the importance of ensuring data security and privacy for European technology users and emphasize the need for all stakeholders to implement and formulate strategies for online safety now and in the future. It can be concluded that securing the Internet architecture and protect it from cybersecurity attacks remains the key challenge to be addressed at European level (Bandyopadhyay \& Sen, 2011, p. 21).

\section{Conclusion}

IoT-based devices and tools are considered to be one of the key drivers of change in the next years. As confirmed by both literature review and consumer data analysis, digitalization and latest technological devices are having a tremendous impact on society and everyday life, from the development of robots, artificial intelligence or connected devices, to smart cities or telemedicine (Eurobarometer 87.1, 2017, p. 3). At the same time, all these technological innovations have one important disadvantage, data privacy and security risks. Because IoT is here to stay and will continue to influence our lives, it is essential that issues related to data security and privacy are discussed and solved accordingly. Furthermore, the urgent need to address cybercrime is intensified 
by the main results of the two European consumer studies (Eurobarometer 87.4, 2017, p. 105). Although extensive actions and campaigns are needed to prevent organized cybercrime and develop protection guidelines for gadgets' suppliers and sellers, it is also very important to educate citizens on what are the criminal activities happening online and how to avoid or reduce them (Eurobarometer 87.4, 2017, p. 105). This step is crucial to increase people's knowledge of online risks and help them handle these risks in a more effective way (Eurobarometer 87.4, 2017, p. 105).

Finally, a number of important study limitations need to be considered. Given the rapid evolution of IoT systems and the increased adoption of technology among European citizens, additional studies are needed to validate and improve the results presented as well as provide a more in-depth discussion on the advantages and disadvantages of IoT devices. Secondly, future studies should also consider multicultural analyses to compare the level of adoption of such technologies in different countries or continents. This is necessary especially for developing countries, where there is a lack of studies on this topic. Finally, further data collection is required to determine for example the factors that influence digital security behaviour among European users or their attitudes towards current digital strategies implemented at European level. In conclusion, we hope this paper will stimulate future research in this area to allow a secure global implementation of IoT and other technological innovations across society.

\section{References}

Acante Solutions (2019). IoT Devices: 5 of the Most Useless 'Smart' Gadgets. Retrieved from https://www.acante.co.uk/iot-devices-5-of-the-most-useless-smart-gadgets/

Addae, J. H., Brown, M., Sun, X., Towey, D., \& Radenkovic, M. (2017). Measuring attitude towards personal data for adaptive cybersecurity, Information and Computer Security, 25(5), 560-579.

Agmon, N. (2019). Deployment Optimization of IoT Devices through Attack Graph Analysis. Retrieved from https://arxiv.org/pdf/1911.06811.pdf

Araral, E. (2020). Why do cities adopt smart technologies? Contingency theory and evidence from the United States, Cities, 106, 1-15.

Atzori, L., Iera, A., \& Morabito, G. (2017). Understanding the Internet of Things: definition, potentials and societal role of a fast evolving paradigm, Ad Hoc Networks, 56(1), 122-140.

Badia-Melis, R., Mishra, P., \& Ruiz-Garcia, L. (2015). Food traceability: new trends and recent advances. A review. Food control, 57, 393-401.

Balte, A., Kashid, A., \& Patil, B. (2015). Security issues in internet of things (IoT): A survey. International Journal of Advanced Research in Computer Science and Software Engineering, 5(4), 450-455.

Bandyopadhyay, D., \& Sen, J. (2011). Internet of things: Applications and challenges in technology and standardization, Wireless Personal Communications, 58(1), 49-69.

Bartneck, C., Nomura, T., Kanda, T., Suzuki, T., \& Kennsuke, K. (2005). Cultural Differences in Attitudes Towards Robots. Proceedings of the AISB Symposium on Robot Companions: Hard Problems and Open Challenges, Human-Robot Interaction, 1-4.

Beier, G., Niehoff, S., \& Xue, B. (2018). More sustainability in industry through industrial internet of things?, Applied Sciences, 8(2), 1-12.

Butun, I., Österberg, P., \& Song, H. (2019). Security of the Internet of Things: Vulnerabilities, Attacks and Countermeasures, IEEE Communications Surveys \& Tutorials, 22(1), 616-644.

Cobb, S. (2018). Why ask the public about cybercrime and cybersecurity?, Retrieved from https://www.welivesecurity.com/2018/10/04/ask-public-cybercrime-cybersecurity/ 
Cvitić, I., Vujić, M., \& Husnjak, S. (2015). Classification of Security Risks in the IoT Environment. $26^{\text {th }}$ DAAAM International Symposium, 731-740.

Edison, S. W., \& Geissler, G. L. (2003). Measuring attitudes towards general technology: Antecedents, hypotheses and scale development, Journal of Targeting, Measurement and Analysis for Marketing, 12(2), 137-156.

Espinoza, H., Kling, G., McGroarty, F., O'Mahony, M., \& Ziouvelou, X. (2020). Estimating the impact of the Internet of Things on productivity in Europe. Heliyon, 6(5), 1-7.

Eurobarometer 87.1 (2017). TNS opinion, Brussels. GESIS Data Archive, Cologne. ZA6861 Data file Version 1.2.0, Retrieved from https://doi.org/10.4232/1.12922

Eurobarometer 87.4 (2017). TNS opinion, Brussels. GESIS Data Archive, Cologne. ZA6924 Data file Version 1.0.0, Retrieved from https://doi.org/10.4232/1.13207

Fatimah, A. Y., Govindan, K., Murniningsih, R., \& Setiawan, A. (2020). Industry 4.0 based sustainable circular economy approach for smart waste management system to achieve sustainable development goals: A case study of Indonesia, Journal of Cleaner Production, 269(1), 1-15.

Garrity, J. (2015). Harnessing the internet of things for global development, Retrieved from https://www.itu.int/en/action/broadband/Documents/Harnessing-IoT-GlobalDevelopment.pdf

Haddud, A., DeSouza, A., Khare, A., \& Lee, H. (2017). Examining potential benefits and challenges associated with the Internet of Things integration in supply chains, Journal of Manufacturing Technology Management, 28(8), 1055-1085.

Howell, D. (2020). M2M: The Future of Cybersecurity, Retrieved from https://www.silicon.co.uk/ networks $/ \mathrm{m} 2 \mathrm{~m} / \mathrm{m} 2 \mathrm{~m}$-the-future-of-cybersecurity-347076?cmpredirect.

IoT Week (2017). Internet of Things Declaration to Achieve the Sustainable Development Goals, Retrieved from https://iotweek.org/internet-of-things-declaration-to-achieve-the-sustaina ble-development-goals/.

Kramp, T., van Kranenburg, R., \& Lange, S. (2013). Introduction to the Internet of Things. In Bassi, A., Bauer, M., Fiedler, M., Kramp, T., van Kranenburg, R., Lange, S., Meissner, S. (Eds.), Enabling Things to Talk (pp. 1-10). New York: Springer.

López-Vargas, A., Fuentes, M., \& Vivar, M. (2020). Challenges and Opportunities of the Internet of Things for Global Development to Achieve the United Nations Sustainable Development Goals, IEEE Access, 8, 202-213.

Lorek, S., \& Spangenberg, J. H. (2014). Sustainable consumption within a sustainable economy beyond green growth and green economies, Journal of Cleaner Production, 63, 33-44.

Maksimovic, M. (2018). Greening the future: Green internet of things (G-IoT) as a key technological enabler of sustainable development. In Dey, N., Hassanien, A.E., Bhatt, C., Ashour, A.S., Satapathy, S.C. (Eds.), Internet of things and big data analytics toward nextgeneration intelligence, 283-313, New York: Springer.

Marquardt, K. (2017). Smart services - characteristics, challenges, opportunities and business models, Proceedings of the International Conference on Business Excellence, 11(1), 789-801.

Mohammadian, H. D., \& Rezaie, F. (2020). i-Sustainability Plus Theory as an Innovative Path towards Sustainable World Founded on Blue-Green Ubiquitous Cities (Case Studies: Denmark and South Korea), Inventions, 5(14), 1-21.

Neagu, G., Vrejoiu, M., Preda, Ş., \& Stanciu, A. (2017). Platforme IoT - Solutii actuale si tendinte de evolutie, Revista Română de Informatică şi Automatică, 27(3), 1-14. 
Nižetić, S., Šolić, P., González-de-Artaza, D. L., \& Patrono, L. (2020). Internet of Things (IoT): Opportunities, issues and challenges towards a smart and sustainable future, Journal of Cleaner Production, 274, 1-32.

O'Donnell, L. (2020). More Than Half of IoT Devices Vulnerable to Severe Attacks, Retrieved from https://threatpost.com/half-iot-devices-vulnerable-severe-attacks/153609/

OECD.AI (2020). National AI policies \& strategies, Retrieved from https://oecd.ai/dashboards

Olmstead, K., \& Smith, A. (2017). Americans and Cybersecurity. Pew Research Center, Retrieved from https://davidellis.ca/wp-content/uploads/2016/09/Pew-Americans-and-Cyber-Security -Jan2017.pdf.

Patton, M., Gross, E., Chinn, R., Forbis, S., Walker, L., \& Chen, H. (2014). Uninvited Connections: A Study of Vulnerable Devices on the Internet of Things (IoT), IEEE Joint Intelligence and Security Informatics Conference, 232-235.

Payne, J., Budhraja, K., \& Kundu, A. (2019). How Secure Is Your IoT Network?, IEEE International Congress on Internet of Things, 1-8.

Roman, R., Najera, P., \& Lopez, J. (2011). Securing the internet of things, Computer, 44(9), 51-58.

Rusu, L. D. (2017). Internet of Things and Romanian Management, Proceedings of the $11^{\text {th }}$ International Management Conference, 11(1), 660-671.

Salam, A. (2019). Internet of Things for Sustainable Community Development - Wireless Communications, Sensing and Systems, New York, Springer.

Santucci, G. (2011). The Internet of Things: The Way ahead. In Vermesan, O., Friess, P. (Eds.), Internet of Things-Global Technological and Societal Trends from Smart Environments and Spaces to Green ICT, Aalborg, River Publishers.

Savu, D., Tomescu, M., \& Băjenaru, L. (2017). Internetul lucrurilor - o nouă paradigmă a conectării în Internet of Things, Revista Română de Informatică şi Automatică, 27(1), 5-16.

Schneider, S. (2019). The impacts of digital technologies on innovating for sustainability. In Bocken, N., Paavo, R., Albareda, L., Verburg, R. (Eds.), Innovation for sustainability, 415-433, New York, Springer.

Sicari, S., Rizzardi, A., Grieco, L. A., \& Coen-Porisini, A. (2015). Security, privacy and trust in Internet of Things: The road ahead, Computer Networks, 76, 146-164.

Statista (2020). Internet usage frequency in the EU 2019, Retrieved from https://www.statista.com/ statistics/422628/europe-internet-usage-frequency/.

Sunyaev, A. (2020). Internet Computing, New York, Springer.

Symanovich, S. (2019). The future of IoT: 10 predictions about the Internet of Things, Retrieved from https://us.norton.com/internetsecurity-iot-5-predictions-for-the-future-of-iot.html.

Thibaud, M., Chi, H., Zhou, W., \& Piramuthu, S. (2018). Internet of Things (IoT) in high-risk Environment, Health and Safety (EHS) industries: A comprehensive review, Decision Support Systems, 108, 79-95.

Tohanean, D., \& Vasilescu, A. (2019). Business Models and Internet of Things, Proceedings of the International Conference on Business Excellence, 13(1), 1192-1203.

Vodafone Group (2019). Vodafone Business - IoT Barometer 2019, Retrieved from https://www. vodafone.com/business/news-and-insights/white-paper/vodafone-iot-barometer-2019.

Wortmann, F., \& Fluchter, K. (2015). Internet of Things: Technology and Value Added, Business \& Information Systems Engineering, 57(3), 221-224.

Zamfiroiu, A., Iancu, B., Boja, C., Georgescu, T., Cartas, C., Popa, M., \& Toma, C.V. (2020). IoT Communication Security Issues for Companies: Challenges, Protocols and The Web of Data, Proceedings of the International Conference on Business Excellence, 14(1), 1109-1120.

DOI: 10.2478/picbe-2021-0101, pp. 1069-1082, ISSN 2558-9652 |

Proceedings of the $15^{\text {th }}$ International Conference on Business Excellence 2021 
Zarei, M., Mohammadian, A., \& Ghasemi, R. (2016). Internet of things in industries: a survey for sustainable development, International Journal of Innovation and Sustainable Development, 10(4), 419-442.

Zhang, Z., Cho, M., Wang, C., Hsu, C., Chen, C., \& Shieh, S. (2014). IoT Security: Ongoing Challenges and Research Opportunities, IEEE $7^{\text {th }}$ International Conference on ServiceOriented Computing and Applications, 230-234. 